\title{
Consequences of outbreeding on phenotypic plasticity in Drosophila mercatorum wings
}

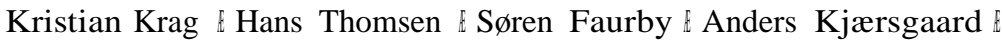 \\ Miguel Tejedo \& Volker Loeschcke \& Cino Pertoldi
}

\begin{abstract}
A multivariate morphometric investigation was conducted on wings of two parthenogenetic Drosophila mercatorum strains and offspring (F1) of crosses between these parthenogenetic strains with highly inbred sexual individuals of the same species. The parental flies and F1 offspring were reared at three different temperatures: 20, 25, or $28^{\circ} \mathrm{C}$. This design allows a comparison of completely homozygous individuals (parental generation) with identical heterozygote offspring (F1), which makes an analysis of phenotypic plasticity of morphometric traits possible, without a potentially confounding effect of genotype-environment interactions, which can increase the phenotypic variability. The same pattern of phenotypic plasticity of wing size between the homozygous parental strains and the heterozygous offspring was found in both strains with an apparent heterotic effect for wing size in the $\mathrm{F} 1$ at $25^{\circ} \mathrm{C}$. At 20 and $28^{\circ} \mathrm{C}$ flies from the parental generation had the biggest wings. Phenotypic plasticity of shape was found to be strain dependent. A reduced level of developmental instability (DI) was found in the F1 as compared to the parental strain only in strain 1 reared at $20^{\circ} \mathrm{C}$ for the wing size and $25^{\circ} \mathrm{C}$ for the wing shape. For all the other treatments higher DI was found in the F1 when the difference was significant, which is suggestive of outbreeding depression. These findings are difficult to interpret since an apparent heterotic effect of size at $25^{\circ} \mathrm{C}$ is accompanied by higher DI (though not significant in strain 2) and complex changes in wing shape. Hence, we cannot conclude whether outbreeding lowers or increases the capacity to respond to environmental change via plastic responses and via changes of the level of DI. The degree of change of
\end{abstract}

Kristian Krag and Hans Thomsen have contributed equally.

K. Krag H. Thomsen S. Faurby (\&) A. Kjærsgaard ( $\&$ ) V. Loeschcke C. Pertoldi Ecology and Genetics, Department of Biological Sciences, University of Aarhus, Ny Munkegade, Building 1540, 8000 Aarhus C, Denmark

e-mail: soren.faurby@biology.au.dk

A. Kjærsgaard

e-mail: anders.kjaersgaard@biology.au.dk

M. Tejedo

Department of Evolutionary Biology, Estación Biológica de Doñana (C.S.I.C.), 41013 Sevilla, Spain 
phenotypic plasticity and DI is trait specific, depending on the environment and on the genotypes which are hybridizing.

Keywords Hybridization Global change Evolutionary potential

Environmental variability Wing size Wing shape

\section{Introduction}

Populations previously isolated may come into secondary contact for anthropogenic reasons. These include passive transport of animals or plants on planes and ships (Ruiz et al. 1997), restocking of wild populations (Hansen 2002) and possibly climatic change. The degree of adaptation is an interaction between the selective pressure and gene flow as high levels of gene flow can reduce or impede the capacity for local adaptation (Comins 1977; Taylor and Georghiou 1979; Roush and Mckenzie 1987) or may introduce new genes for future adaptation (Slatkin 1995). Thus, the ideal amount of gene flow is a balance between too little gene flow leading to loss of genetic variation and potential inbreeding and too much gene flow of poorly adapted genes (outbreeding depression; Marr et al. 2002; Vergeer et al. 2004; Sagvik et al. 2005; Edmands 2007). Mating between individuals from different populations can lead to heterosis in the first generation, after which outbreeding depression may occur (Dobzhansky 1950; Andersen et al. 2002; Edmands 2007). It may, however, also occur in the F1 generation due to factors such as underdominance, epistatic interactions, heterozygote-heterozygote interactions or disruption of local adaptation (Edmands 2007).

The traits underlying fitness and adaptation to changing environmental conditions are generally of a quantitative nature (Lynch 1996). A quantitative genetic approach is therefore the most direct avenue toward a better understanding of the adaptive potential of populations and of the consequences of outbreeding depression. Experiments investigating the fate of populations with little genetic variability are very difficult to carry out in the wild but quantitative genetic models have investigated whether wild populations will adapt or go extinct in response to continuous environmental change (Bürger and Lynch 1995; Lande and Shannon 1996). Gomulkiewicz and Holt (1995) concluded that only large populations experiencing relatively small environmental changes are likely to be rescued by evolution. Ultimately, populations only persist if the rate of adaptive evolution at least matches the rate of environmental change (Bürger and Lynch 1995). Given that many populations of conservation concern are too small to harbor enough genetic variability for an evolutionary response, their survival must rely on the capacity to react to environmental changes in a plastic way (Merilä 1997; Pigliucci 2005).

Since the distributional range of a species is temporally and probably also spatially heterogeneous a single phenotype is unlikely to be associated with high fitness throughout its range (Pertoldi et al. 2005). Modeling approaches have shown that to optimize fitness, phenotypic plasticity evolves by trading the adaptation to acquire resources against the costs of maintaining a potential for being plastic (Ernande and Dieckmann 2004). Such plastic responses include changes in behavior, physiology, morphology, growth, life history and demography, and can be expressed either within the lifespan of an individual or across generations (Merilä 1997; Faurby et al. 2005).

The relationship between plasticity and heterozygosity has been a subject of controversy in the literature. One theory suggests that higher heterozygosity leads to lower plasticity and developmental instability (DI) but empirical studies generally fail to find 
this (Scheiner 1993). DI is considered as an integral component of fitness and is defined as the incapacity of an organism to produce an optimal phenotype under a range of environments and genotypes. Failure of this buffering mechanism has been shown to increase with the level of environmental and genetic stress (for a review see Palmer 1996; Pertoldi et al. 2006a).

Another process governing variation is canalization. While phenotypic plasticity refers to the ability of a genotype to produce different phenotypes in different environments, canalization refers to the ability of different genotypes to produce the same phenotype in a given environment (Hoffmann and Woods 2001). The relationship between DI and canalization is controversial similar to the relationship between DI and heterozygosity. Hoffmann and Woods (2001) found no general relationship between DI and canalization in a small review of the data available at the time. A later study, however, showed that such a relationship may be present for wing shape, as a significant correlation between DI and canalization was found for this trait, but not for wing size (Breuker et al. 2006). The authors argued that this was caused by tighter genetic control of wing shape than wing size. As pointed out by Stearns and Kawechi (1994) plasticity and canalization are neither mutually exclusive nor dependent on each other. Furthermore, a plastic process can be strictly canalized in one environment but not in another.

Given the evolutionary importance of phenotypic plasticity and DI, there is an urgent need to improve our understanding of the consequences of outbreeding on these (Pertoldi et al. 2007), avoiding the potentially confounding effect of genotype by environment interactions which can increase the phenotypic variability. In this study we have attempted to investigate this scenario using Drosophila mercatorum as model organism. We have analysed size and shape of the wings, in parental flies and crosses between two different completely homozygous parthenogenetic strains and a sexually reproducing highly inbred and virtually homozygous strain reared at three different temperatures. We expected a reduced level of DI and phenotypic plasticity and an increased mean of wing size in the F1 generation compared to the parental flies at all the three temperatures as a result of heterosis, since wing size is a fitness surrogate in Drosophila. Studies have shown that body size and wing size are correlated (Norry and Vilardi 1996) and that larger body size influences fitness characters (Ruiz et al. 1991).

Material and methods

Experimental design

We used three different strains of D. mercatorum; a sexually reproducing strain of Brazilian origin, which has been inbred by consecutive brother-sister mating for more than 20 generations and two parthenogenetic strains. The first of the parthenogenetic strains is Iv-23-olm, isolated from a sexual population in Hawaii in 1990 (Kramer and Templeton 2001) and will hereafter be referred to as strain 1. The second is Brazil 1 from Faurby et al. (2005) which will be referred to as strain 2. Parthenogenetic D. mercatorum are facultative parthenogenetic and reproduce only parthenogenetically in the absence of males.

Prior to the experiment all flies were kept at $25^{\circ} \mathrm{C}$ at a $12: 12 \mathrm{~h}$ light:dark cycle in vials containing instant Drosophila medium (Carolina Biological Supply, Burlington, NC, USA) and added live yeast. At all time prior to and during the experiment, the number of offspring in each vial was well below critical densities for effects of crowding and competition between the larvae to be significant. Furthermore, we only used progeny of 
3-6 days old mothers to minimize any maternal effects of age, as DI and wing size in progeny has been shown to increase with maternal age in Drosophila (Røgilds et al. 2005; Faurby et al. 2005).

We produced a hybrid generation by mating males from the highly inbred line with parthenogenetic females. Vials with one male and three facultative parthenogenetic females were produced for each combination of parthenogenetic strain (strain 1 or strain 2) and temperature $\left(20,25\right.$, or $\left.28^{\circ} \mathrm{C}\right)$. The results of these matings are referred to as the $\mathrm{F} 1$ generation. The $\mathrm{F} 1$ generation was compared to what we refer to as the parental generation, which is parthenogenetic flies reared at 20,25 , or $28^{\circ} \mathrm{C}$ from parents reared at $25^{\circ} \mathrm{C}$ of each strain respectively. Egg laying took place at $25^{\circ} \mathrm{C}$ and afterwards the vials were transferred to the respective temperatures. The parental generation and the F1 generation were reared simultaneously to reduce any temporal environmental variation. Although the parental generation flies are not the actual mothers they are genetically identical to them and therefore, this method allows for the comparison of parents and offspring at different temperatures without confounding maternal effects of temperature. Upon hatching flies were transferred to smaller vials and stored at $-20^{\circ} \mathrm{C}$.

\section{Analyses}

Wings of flies were removed and placed in a droplet of lactic acid, on a microscope slide and covered with a cover slip. Wings were named referring to strain and temperature and were photographed using a camera attached to a dissecting microscope and a computer with the software IM1000 version 1.2 and measured by the use of the software package ImageJ version 1.33u (Rasband 2001). We followed the design by Faurby et al. (2005) and measured 36 metric distances between nine different landmarks on the left wing (Fig. 1). The number of wings measured per temperature ranged from 282 to 347 . The females of the sexual strains were not utilized for the comparisons of the level of DI and phenotypic plasticity as they are significantly smaller than the parthenogenetic and the F1 generations. Such differences in size will create problems associated with the scaling effect of the mean with the variance, which cannot be corrected properly by the use of the coefficient of variation unless there is a squared relationship between these two parameters (Taylor 1961).

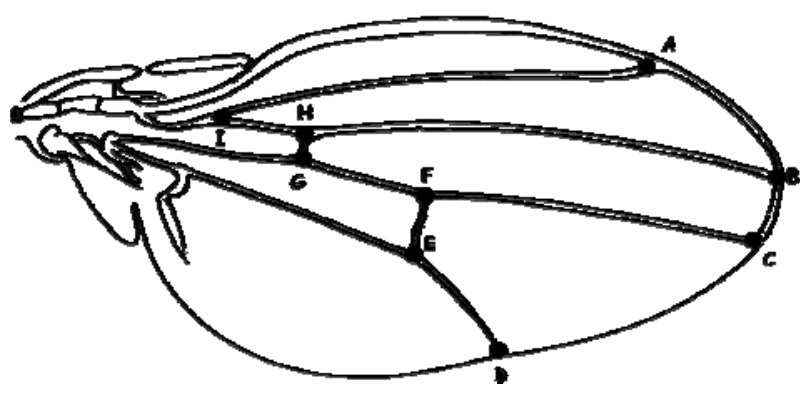

Fig. 1 The nine landmarks used for the analysis. They were the end of the 2nd to the 5th longitudinal vein, the crosses between the posterior cross vein and the 4th and 5th longitudinal vein, the crosses between the anterior cross vein and the 2nd and 3rd longitudinal vein and the cross between the 2nd and 3rd longitudinal vein. Picture replicated from Faurby et al. (2005) 
A multivariate analysis was performed, in order to use all the measurements and to reduce considerably the number of tests performed (Rice 1989).

A principal component analysis (PCA) following Marcus (1990) was carried out on the covariance matrix derived from the wing measurements. This analysis classifies phenotypic variation into independent components that can be used to dissect genetic networks regulating complex biological systems (Chase et al. 2002).

If size variation is present in the data and the loadings of principal component 1 (PC1) are either all positive or all negative, PC1 can be said to summarize the within-sample size variation (Bookstein 1989). Shape can be defined as the subspace of dimensions one less than the number of measured variables and quantifies the variation that cannot be explained by size variation and allometric relationships. It has been suggested that functionally independent parts of the wings should vary independently among the loci controlling quantitative traits, and therefore should be associated with different PCs (Klingenberg and Leamy 2001).

All the wings were grouped by genotype (the two parthenogenetic parental or the respective F1 offspring from their crosses with the inbred sexual strain and rearing temperature $\left(20,25\right.$, and $\left.28^{\circ} \mathrm{C}\right)$.

A resampling F- and t-test was conducted in order to test the differences in variances (which are considered as an estimate of DI in an isogenic strain) and means of the PC scores between the wings of the parthenogenetic parentals and the F1 offspring reared at the same temperature and at different temperatures respectively. These tests, unlike normal F- and t-tests are less sensitive toward deviations from normality, but still use $100 \%$ of the information unlike non-paremetric statistics (Davison and Hinkley 1997). A Bonferroni correction for multiple comparisons was conducted both for the F- and t-test (Rice 1989). As offspring were all kept under identical environmental conditions, it is assumed that the environmental variability $\left(\mathbf{r}^{2} \mathrm{e}\right)$ encountered by the offspring during development was of the same magnitude as the $\mathbf{r}^{2}$ e encountered by the parental generation $\left(\mathbf{r}^{2} \mathrm{e}=\mathrm{k}\right)$. Hence, differences in phenotypic variability $\left(\mathbf{r}^{2} \mathrm{p}\right)$, among the offspring reared at different temperatures and among the parental generation are ascribed to differences in DI.

The differences in the degree of phenotypic plasticity between the parental strains and F1 strains were assessed by an analysis of parallelism of the reaction norms across the temperature gradient. A specific test was performed on the differences in the shape of the reaction norms by examining the strain 9 temperature interaction by means of two-ways ANOVA. A significant interaction implies strain variation in plasticity across temperatures; non-significance indicates that strain reaction norms run parallel to one another. In addition, the differences in the degree of phenotypic plasticity between the parental strains and the F1 strains were tested by comparing the absolute values of the slopes of the regressions between 20 and $25^{\circ} \mathrm{C}, 20$ and $28^{\circ} \mathrm{C}$, and 25 and $28^{\circ} \mathrm{C}$, respectively by means of a Z-test (Zar 1999). Significant differences between the absolute values of the slopes between generations imply significant differences of the level of phenotypic plasticity between the two generations.

All the statistic analyses were performed using the software PAST (Hammer et al. 2001) and STATVIEW (2006).

\section{Results}

The different groups: the highly inbred strain reproducing sexually, the parental parthenogenetic strains and the F1 offspring reared at the three temperatures, could generally be 
distinguished by their loadings on PC1 and PC2 axes (despite some overlap), indicating that the hybridization event caused changes both in the size and the shape of the wings (Fig. 2a, b). The first principal component, which summarizes the size variation among the three temperatures, explained $90.9 \%$ of the total variance. The inbred sexual parental flies maintained at $25^{\circ} \mathrm{C}$ were generally the smallest and both the parthenogenetic parent flies and the F1 offspring became smaller as temperature increased. Principal component 2, which summarizes the most important temperature induced shape changes, explained $3.41 \%$ of the remaining variation and distinguished parental groups and offspring with the former having the highest values.

The specific wing changes were rather complex. All lengths measured loaded on both PC1 and PC2 but the three traits, which loaded the most on PC2 were BC, GI, and HI (see Fig. 1) and all three loaded negatively (results not shown). Higher loadings thus result in relatively wider wings whereas lower loadings result in relatively narrower wings.

Tests of mean and variance of loadings on the two axes of offspring and parental group within the individual strain at each temperature are presented in Table 1 and Fig. 2a, b. It shows that for PC1, the F1 offspring were significantly larger than the parthenogenetic parents at $25^{\circ} \mathrm{C}$, whereas for 20 and $28^{\circ} \mathrm{C}$ the offspring were smaller except in one case were the difference was non-significant. For PC2 the parents always had significantly larger values (see Table 1 and Fig. 2a, b).

The pattern of variance (DI) is less clear but the parents generally had smaller variances on both PC1 and PC2 with only two exceptions observed for strain 1: PC1 at $20^{\circ} \mathrm{C}$ and PC2 at $25^{\circ} \mathrm{C}$ (see Table 1). In strain 2 the variance in the parents only exceeded that of the offspring in one case: PC2 at $20^{\circ} \mathrm{C}$. This was however non-significant. Significant differences were found in three of the five cases where the variance of the parents was lower than that of the offspring: PC 1 at $28^{\circ} \mathrm{C}, \mathrm{PC} 2$ at $25^{\circ} \mathrm{C}$ and $\mathrm{PC} 2$ at $28^{\circ} \mathrm{C}$.

The results of the two-ways ANOVA which was used for testing the parallelisms of the reaction norms were all highly significant both for PC1 and PC2 and both for strain 1 and 2 $(P \backslash 0.01)$ for the parental versus the $F 1$ strain $(8.534 \backslash F \backslash 1344.56)$, for the temperatures $(19.47 \backslash F \backslash 4365)$, and for the interaction between strain and temperature (25.24 \F\130.31). This indicates that the reaction norms in the parental and the F1 offspring were not parallel to each other, which implies differences in plasticity.

The plastic responses in wing size (PC1) to temperature changes were clearly nonlinear. The size reduction in the offspring was relatively smaller than in the parental strain from 20 to $25^{\circ} \mathrm{C}$ whereas it was relatively larger from 25 to $28^{\circ} \mathrm{C}$. All comparisons involving $25^{\circ} \mathrm{C}$ showed differences in slopes between offspring and parents whereas there were no differences in the slopes from 20 to $28^{\circ} \mathrm{C}$ in any of the strains (see Fig. 3).

The plastic responses in wing shape to temperature changes (PC2) showed a clearer pattern. In both strains the parents were more plastic from 20 to $28^{\circ} \mathrm{C}$ and from 20 to $25^{\circ} \mathrm{C}$ although the difference was non-significant in one of the strains from 20 to $28^{\circ} \mathrm{C}$. From 25 to $28^{\circ} \mathrm{C}$ the offspring were more plastic in strain 1 but this appears to be a strain specific phenomenon (Fig. 3).

\section{Discussion}

The wing size of the flies was found to be negatively correlated with temperature both in the parental and the F1 flies, which is concordant with numerous previous studies (e.g., James and Partridge 1998). The intermediate temperature is believed to be an ideal temperature for the flies since they were all established at $25^{\circ} \mathrm{C}$ from flies maintained at this 

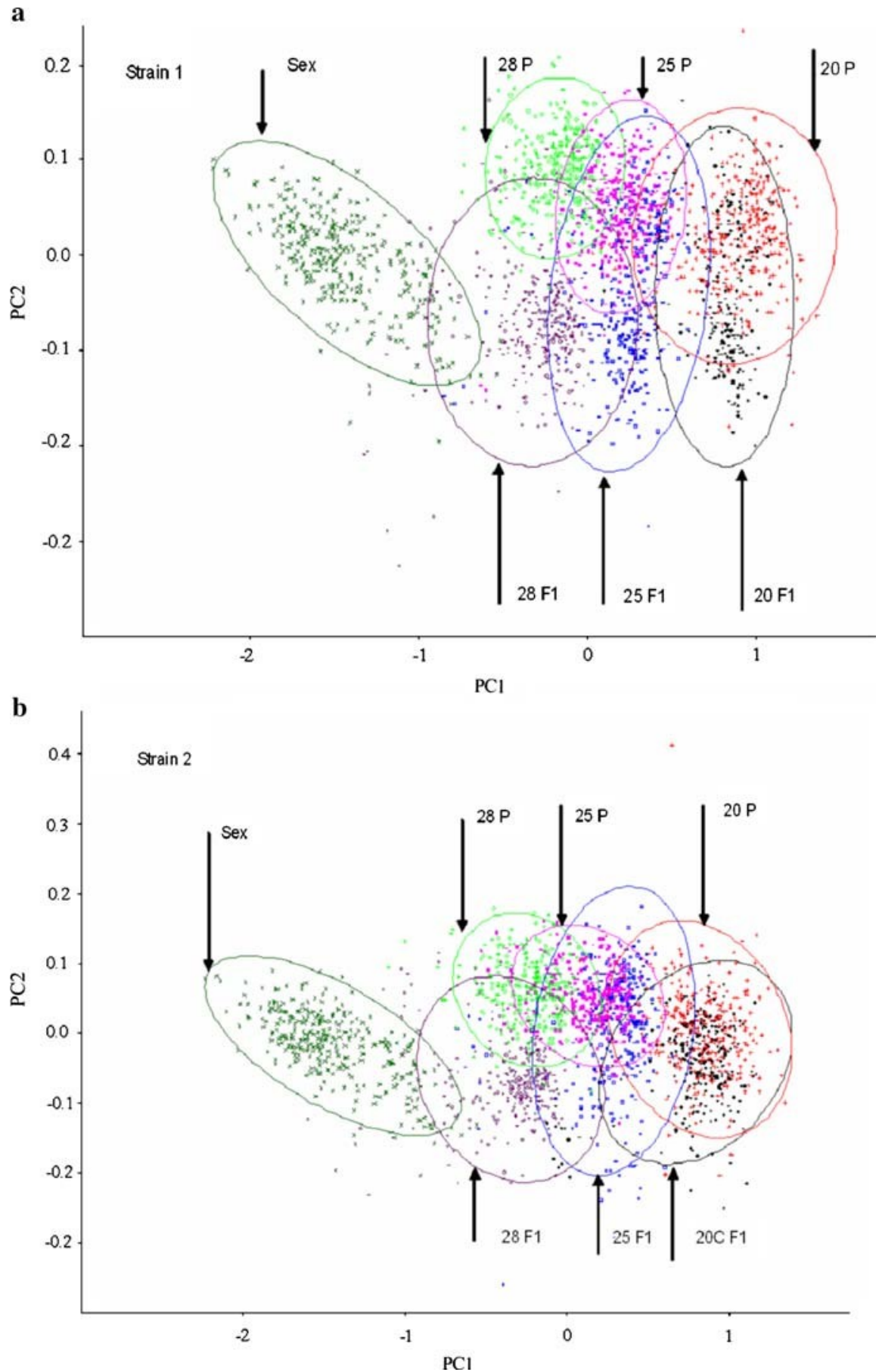

Fig. 2 (a, b) Plots of the first two principal components (PC1 and PC2) of the principal component analysis (with $95 \%$ confidence interval ellipses) of the two parental strains reared at 20,25 , and $28^{\circ} \mathrm{C}$, the $\mathrm{F} 1$ generation reared at 20,25 , and $28^{\circ} \mathrm{C}$ and the sexually reproducing inbred strain reared at $25^{\circ} \mathrm{C}$ 
Table 1 The results of the principal component analysis, the three first columns note the principal component, developmental temperature, and strain

\begin{tabular}{|c|c|c|c|c|c|c|c|c|}
\hline \multirow[t]{2}{*}{ PC } & \multirow[t]{2}{*}{ Temperature $\left({ }^{\circ} \mathrm{C}\right)$} & \multirow[t]{2}{*}{ Strain } & \multicolumn{2}{|l|}{ Mean 1} & & \multicolumn{2}{|c|}{${\text { Variance } s^{2}}^{2}$} & \\
\hline & & & $\mathrm{P}$ & $\mathrm{F} 1$ & & $\mathrm{P}$ & $\mathrm{F} 1$ & \\
\hline 1 & 20 & 1 & 6.6325 & 6.0556 & $\mathrm{P}[\mathrm{F} 1 * * *$ & 3.2036 & 1.6545 & $\mathrm{P}[\mathrm{F} 1 * * *$ \\
\hline 1 & 20 & 2 & 6.0765 & 5.9883 & ns & 2.8790 & 2.9095 & ns \\
\hline 1 & 25 & 1 & 1.3109 & 1.7522 & $\mathrm{P} \backslash \mathrm{F} 1 * * *$ & 1.4144 & 1.9940 & $\mathrm{P} \backslash \mathrm{F} 1 * *$ \\
\hline 1 & 25 & 2 & 0.7479 & 2.0637 & $\mathrm{P} \backslash \mathrm{F} 1 * * *$ & 2.1907 & 2.3464 & ns \\
\hline 1 & 28 & 1 & -1.5532 & -2.1683 & $\mathrm{P}[\mathrm{F} 1 * * *$ & 1.5974 & 3.4343 & $\mathrm{P} \backslash \mathrm{F} 1 * * *$ \\
\hline 1 & 28 & 2 & -1.9388 & -2.3602 & $\mathrm{P}\lceil\mathrm{F} 1 * *$ & 1.9224 & 2.8357 & $\mathrm{P} \backslash \mathrm{F} 1 * *$ \\
\hline 2 & 20 & 1 & 0.2403 & -0.5622 & $\mathrm{P}[\mathrm{F} 1 * * *$ & 0.5822 & 1.0143 & $\mathrm{P} \backslash \mathrm{F} 1 * * *$ \\
\hline 2 & 20 & 2 & 0.0932 & -0.5702 & $\mathrm{P}[\mathrm{F} 1 * * *$ & 0.8723 & 0.7896 & ns \\
\hline 2 & 25 & 1 & 0.7836 & -0.5478 & $\mathrm{P}[\mathrm{F} 1 * * *$ & 0.4767 & 1.2661 & $\mathrm{P}\lceil\mathrm{F} 1 * * *$ \\
\hline 2 & 25 & 2 & 0.8587 & 0.0519 & $\mathrm{P}\left[\mathrm{F} 1^{* * * *}\right.$ & 0.3875 & 1.4841 & $\mathrm{P} \backslash \mathrm{F} 1 * * *$ \\
\hline 2 & 28 & 1 & 1.3358 & -1.0888 & $\mathrm{P}\lceil\mathrm{F} 1 * * *$ & 0.3416 & 0.9195 & $\mathrm{P} \backslash \mathrm{F} 1 * * *$ \\
\hline 2 & 28 & 2 & 0.8895 & -1.0340 & $\mathrm{P}\lceil\mathrm{F} 1 * * *$ & 0.4691 & 0.8293 & $\mathrm{P} \backslash \mathrm{F} 1 * * *$ \\
\hline
\end{tabular}

In each case the mean (1) and variance $\left(\mathrm{s}^{2}\right)$ of the parthenogenetic parents $(\mathrm{P})$ and the offspring (F1) are compared. The tests for differences between $\mathbf{1}$ and $\mathrm{s}^{2}$ are Bonferroni corrected $(\mathrm{k}=12)$

temperature and have also been maintained at this temperature for many generations afterwards. The size of the offspring generation is lower at 20 and $28^{\circ} \mathrm{C}$ than that of the parental parthenogenetic flies. The reason for this is that the sexual flies are smaller than the parthenogenetic ones and therefore the offspring would be smaller than the parthenogenetic parents if size is mainly governed by additive genetic effects. The larger size of the offspring at $25^{\circ} \mathrm{C}$ therefore indicates a heterotic effect. This finding is interesting since heterosis is normally assumed to be more important in stressful environments because heterozygosity is believed to increase the buffering capacity and decrease DI (Lerner 1954; Pertoldi et al. 2006a, b). It has, however, been suggested that more genes will affect a trait in benign conditions and that their expression will be stronger (Wu 1998). This would lead to larger effects of differences in heterozygosity in benign environments as compared to more stressful ones, which is what is observed for wing size in this study.

The variances of the first two PCs at each temperature and strain are used as estimators of DI. In most cases the variance of the offspring is higher than that of the parents (Table 1). This increased DI observed in the F1 both for PC1 and PC2 at several temperatures indicates that outbreeding depression may be manifest already in the F1 generation. This could have contributed to the observed size of the offspring which was lower at 20 and $28^{\circ} \mathrm{C}$ than that of the parental parthenogenetic flies. Developmental instability has, however, also been interpreted as a bet-hedging strategy in an unpredictable environment where increased DI with increased stress could be considered, in an evolutionary context, as a mechanism of defense (Simmons and Johnston 1997). Selection can work only on differences in phenotypes and phenotypic plasticity and DI can reduce the correlation between genotype and phenotype.

The shape of the wings of the parents and offspring shows different patterns at different temperatures. The wings of the parents become relatively wider at higher temperatures whereas the wings of the offspring become relatively narrower at higher temperatures. Similar results have been found in Loeschcke et al. (1999) and are difficult to interpret, but 
Strain 1 PC1
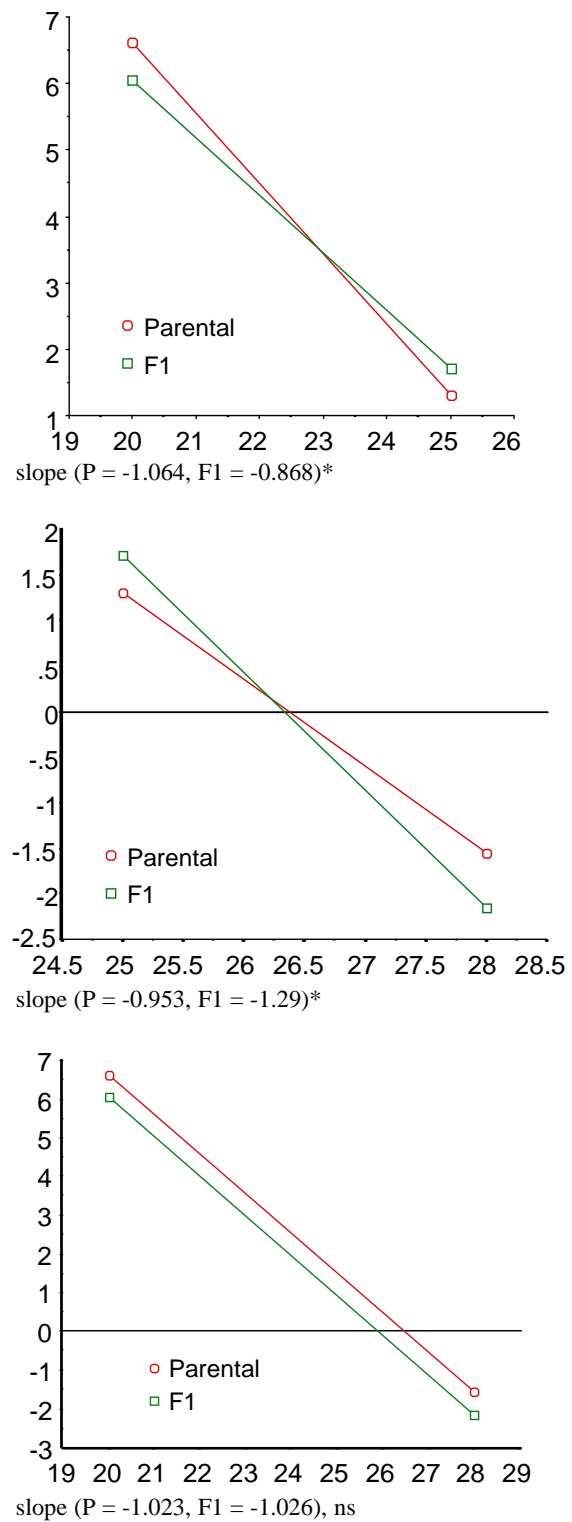

Strain 1 PC2
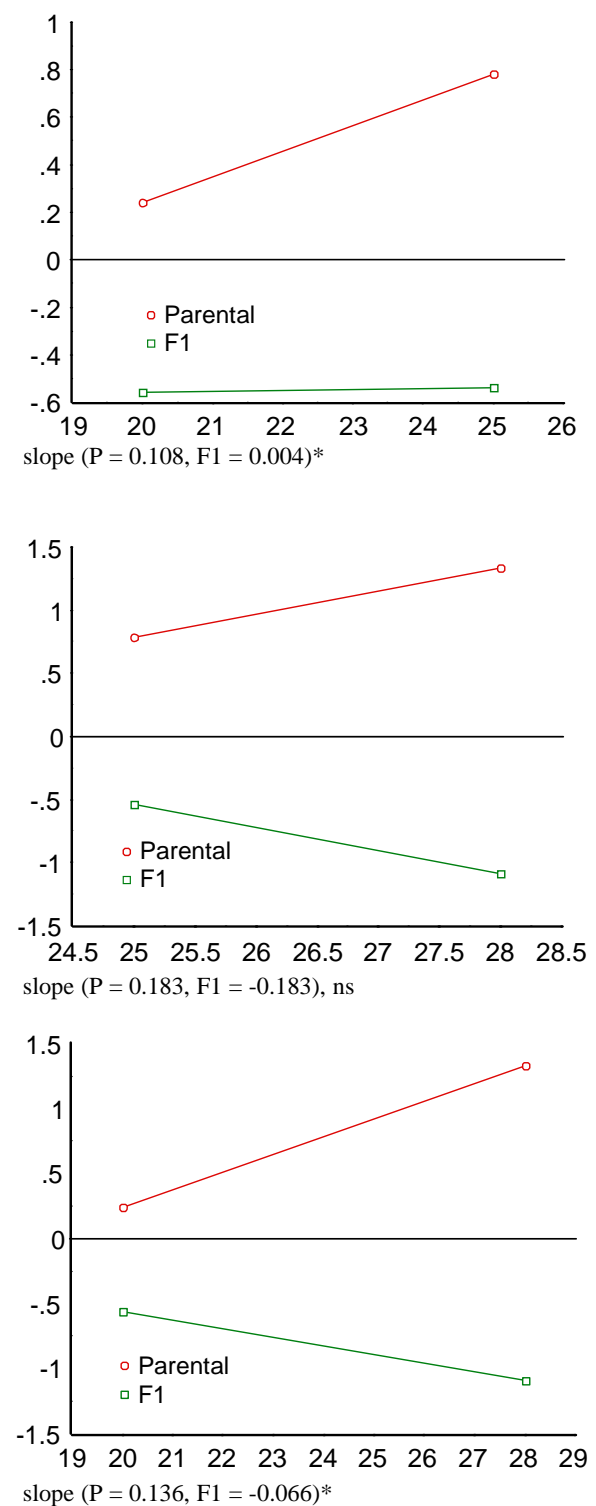

Fig. 3 (a, b) Reaction norms of principal components (vertical axes) one and two for the two strains (strain 1 (a) and strain 2 (b)). Separate figures are shown for each temperature (horizontal axis) comparison (20-25, $25-28$, and $20-28^{\circ} \mathrm{C}$ ) in each principal component in each strain. Comparisons showing significant differences in the absolute value of the slope are marked with an asterisk

good evidence for the fitness of wing shape has been found in mark-capture studies (Kölliker-Ott et al. 2003) and other studies also indicate a fitness relation between wing shape and temperature (Cavicchi et al. 1991). It is therefore interesting that the 
b
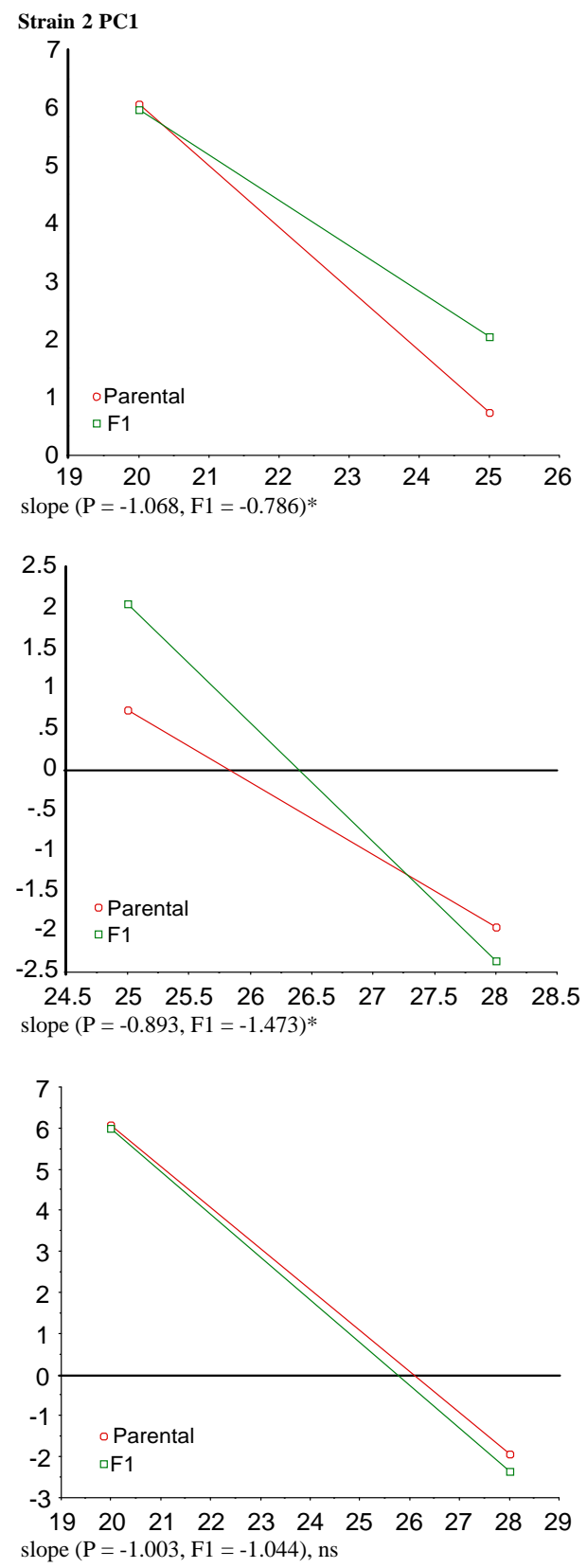

Strain 2 PC2
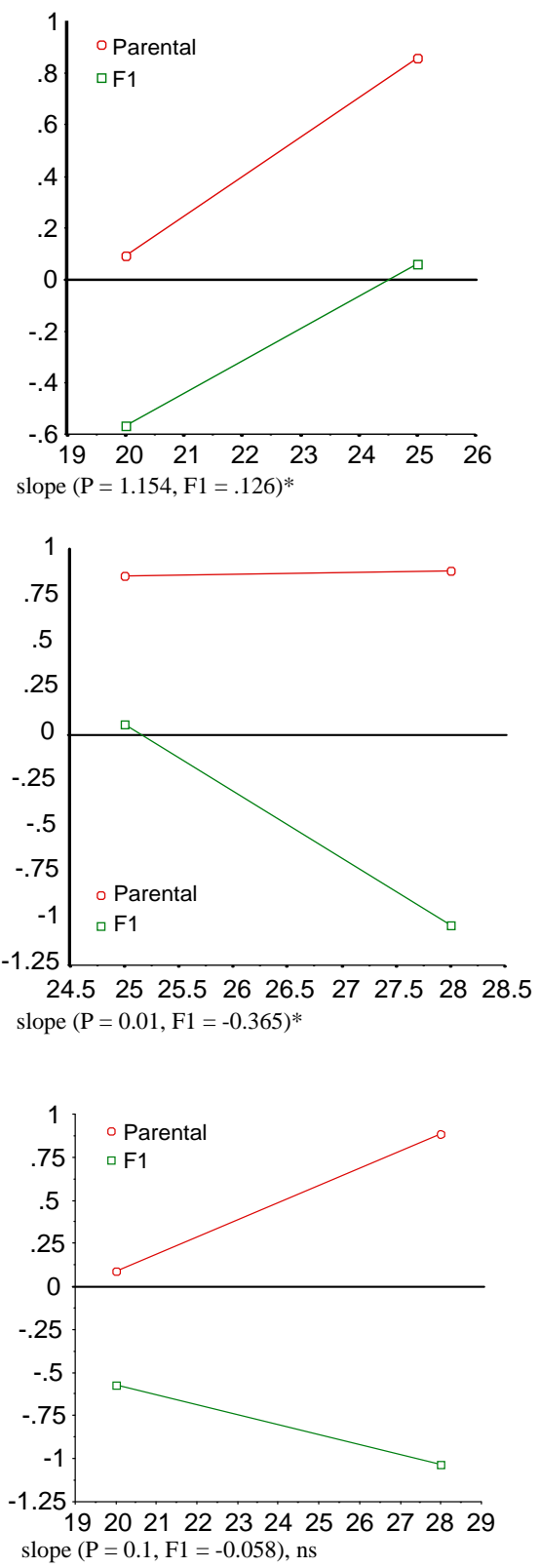

Fig. 3 continued

heterozygous offspring and homozygous parental types reacted in different ways as one of the reaction norms may be maladaptive. Changes in the same wing landmarks as those responsible for the changes in wing size and shape in this study were also observed in a 
previous study on maternal effects working on the same parthenogenetic strains (Kjærsgaard et al. 2007). The lack of a concordant pattern between the way in which size and shape behave could also be attributed to the fact that genes regulate the shape of the traits more tightly than they regulate size and that more genes are involved in its regulation (Birdsall et al. 2000; Workman et al. 2002).

The evolutionary significance of phenotypic plasticity has been discussed in many contexts (Schlichting and Pigliucci 1998; West-Eberhard 2003; Røgilds et al. 2005). This study shows that the degree of genetic variation present in a population will affect the level of DI and the plastic responses to a change in temperature in a way which is genotype, trait and environment specific. The change of the genetic composition in a population may contribute to an acceleration or deceleration of the current trends in species dynamics, especially if environmental changes affect fitness related traits. The same DI and plasticity which can increase the short-term ability to respond to environmental changes can also reduce the ability for long-term changes (Sultan 1996).

Acknowledgements We thank two anonymous reviewers for invaluable comments and suggestions on the manuscript. The work was supported by grants from the Danish Natural Sciences Research Council (21-010526 and 21-03-0125) to CP and VL and CP also by the Marie Curie Fellowship of the European Community Host Development program under contract number HPMD-CT-2000-00009. Finally we wish to thank the European Science Foundation funded ConGen program.

\section{References}

Andersen DH, Pertoldi C, Scali V, Loeschcke V (2002) Intraspecific hybridization, developmental stability and fitness in Drosophila mercatorum. Evol Ecol Res 4:603-621

Birdsall K, Zimmerman E, Teeter K, Gibson G (2000) Genetic variation for the positioning of wing veins in Drosophila melanogaster. Evol Dev 2:16-24

Bookstein FL (1989) Size and shape - a comment on semantics. Syst Zool 38:173-180

Breuker CJ, Patterson JS, Klingenberg CP (2006) A single basis for developmental buffering of Drosophila wing shape. PLOS ONE 1(1):e7

Bürger R, Lynch M (1995) Evolution and extinction in a changing environment - a quantitative-genetic analysis. Evolution 49:151-163

Cavicchi S, Giorgi G, Natali V, Guerra D (1991) Temperature-related divergence in experimental populations of Drosophila melanogaster. Fourier and centroid analysis of wing shape and relationship between shape variation and fitness. J Evol Biol 4:141-159

Chase K, Carrier DR, Adler FR, Jarvik TE, Ostrander A, Lorentzen TD, Lark KG (2002) Genetic basis for systems of skeletal quantitative traits: principal component analysis of the canid skeleton. Proc Natl Acad Sci USA 99:9930-9935

Comins HN (1977) Development of insecticide resistance in presence of migration. J Theor Biol 64: 177-197

Davison AC, Hinkley DV (1997) Bootstrap methods and their applications. Cambridge University Press, Cambridge

Dobzhansky T (1950) Genetics of natural populations 19. Origin of heterosis through natural selection in populations of Drosophila pseudoobscura. Genetics 35:288-302

Edmands S (2007) Between a rock and a hard place: evaluating the relative risks of inbreeding and outbreeding for conservation and management. Mol Ecol 16:463-475

Ernande B, Dieckmann U (2004) The evolution of phenotypic plasticity in spatially structured environments: implications of intraspecific competition, plasticity costs and environmental characteristics. J Evol Biol 17:613-628

Faurby S, Kjærsgaard A, Pertoldi C, Loeschcke V (2005) The effect of maternal and grandmaternal age in benign and high temperature environments. Exp Gerontol 40:988-996

Gomulkiewicz R, Holt RD (1995) When does evolution by natural selection prevent extinction. Evolution 49:201-207

Hammer Ø, Harper DAT, Ryan PD (2001) Past: paleontological statistics software package for education and data analysis. Palaeontol Electron 4(1): 9 pp 
Hansen MM (2002) Estimating the long-term effects of stocking domesticated trout into wild brown trout Salmo trutta populations: an approach using microsatellite DNA analysis of historical and contemporary samples. Mol Ecol 11:1003-1015

Hoffmann AA, Woods R (2001) Trait variability and stress: canalisation, developmental stability and the need for a broad approach. Ecol Lett 4:97-101

James AC, Partridge L (1998) Geographic variation in competitive ability in Drosophila melanogaster. Am Nat 151:530-537

Kjærsgaard A, Faurby S, Andersen DH, Pertoldi C, David JR, Loeschcke V (2007) Effects of temperature and maternal and grandmaternal age on wing shape in parthenogenetic Drosophila mercatorum. J Therm Biol 32:59-65

Klingenberg CP, Leamy LJ (2001) Quantitative genetics of geometric shape in the mouse mandible. Evolution 55:2342-2352

Kölliker-Ott UM, Blows MW, Hoffmann AA (2003) Are wing size, wing shape and asymmetry related to field fitness of Trichogramma egg parasitoids? Oikos 100:563-573

Kramer MG, Templeton AR (2001) Life-history changes that accompany the transition from sexual to parthenogenetic reproduction in Drosophila mercatorum. Evolution 55:748-761

Lande R, Shannon S (1996) The role of genetic variation in adaptation and population persistence in a changing environment. Evolution 50:434-437

Lerner IM (1954) Genetic homeostasis. Oliver and Boyd, London

Loeschcke V, Bundgaard J, Barker JSF (1999) Reaction norms across and genetic parameters at different temperatures for thorax and wing size traits in Drosophila aldrichi and D buzzatii. J Evol Biol 12: 605-623

Lynch M (1996) A quantitative genetic perspective on conservation issues. In: Avise JC, Hamrick JL (eds) Conservation genetics: case histories from nature. Chapmann \& Hall, New York, pp 471-501

Marcus LF (1990) Traditional morphometrics. In: Rohlf FJ, Bookstein FL (eds) Proceedings of the Michigan morphometrics workshop. University of Michigan Zoological Museum, Michigan, Ann Arbor

Marr AB, Keller LF, Arcese P (2002) Heterosis and outbreeding depression in descendants of natural immigrants to an inbred population of song sparrows Melospiza melodia. Evolution 56:131-142

Merilä J (1997) Expression of genetic variation in body size of the collared flycatcher under different environmental conditions. Evolution 51:526-536

Norry M, Vilardi JC (1996) Size-related sexual selection and yeast diet in Drosophila buzzatii (Diptera, Drosophilidae). J Insect Behav 9:329-338

Palmer AR (1996) Waltzing with asymmetry. Bioscience 46:518-532

Pertoldi C, Bijlsma R, Loeschcke V (2007) Integrating population genetics and conservation biology: merging theoretical, experimental and applied approaches. Conserv Genet 8:1267-1268

Pertoldi C, Kristensen TN, Andersen DH, Loeschcke V (2006a) Developmental instability as an estimator of genetic stress. Heredity 96:122-127

Pertoldi C, Røgilds A, Andersen DH, Loeschcke V (2005) Heat-induced maternal effects in Drosophila mercatorum and its evolutionary consequences. Evol Ecol Res 7:203-217

Pertoldi C, Sørensen JG, David JR, Loeschcke V (2006b) Lerner's theory on the genetic relationship between heterozygosity, genomic co-adaptation, and developmental instability revisited. Evol Ecol Res 8:1487-1498

Pigliucci M (2005) Evolution of phenotypic plasticity: where are we going now? Trends Ecol Evol 20: 481-486

Rasband W (2001) National Institutes of Health, USA. http://www.rsb.info.nih.gov/ij/

Rice WR (1989) Analyzing tables of statistical tests. Evolution 43:223-225

Røgilds A, Andersen DH, Pertoldi C, Dimitrov K, Loeschcke V (2005) Maternal and grandmaternal age effects on developmental instability and wing size in parthenogenetic Drosophila mercatorum. Biogerontology 6:61-69

Roush RT, Mckenzie JA (1987) Ecological genetics of insecticide and acaricide resistance. Annu Rev Entomol 32:361-380

Ruiz GM, Carlton JT, Grosholz ED, Hines AH (1997) Global invasions of marine and estuarine habitats by non-indigenous species: mechanisms, extent, and consequences. Am Zool 37:621-632

Ruiz A, Santos M, Barbadilla A, Quezada-Diaz JK, Hasson E, Fontdevila A (1991) Genetic variance for body size in a natural population of Drosophila buzzatii. Genetics 128:739-750

Sagvik J, Uller T, Olsson M (2005) Outbreeding depression in the common frog Rana temporaria. Conserv Genet 6:205-211

Scheiner SM (1993) Genetics and evolution of phenotypic plasticity. Annu Rev Ecol Syst 24:35-68

Schlichting CD, Pigliucci M (1998) Phenotypic evolution: a reaction norm perspective. Sinauer Associates Inc., MA, USA 
Simmons AM, Johnston MO (1997) Developmental stability as a bet-hedging strategy. Oikos 80:401-406 Slatkin M (1995) A measure of population subdivision based on microsatellite allele frequencies. Genetics 139:457-462

STATVIEW (2006) Abacus. http://www.statview.com

Stearns SC, Kawechi TJ (1994) Fitness sensitivity and canalisation of life-history traits. Evolution 48: 1438-1450

Sultan SE (1996) Evolutionary implications of phenotypic plasticity in plants. J Evol Biol 21:127-178

Taylor LR (1961) Aggregation, variance and the mean. Nature 189:732-735

Taylor CE, Georghiou GP (1979) Suppression of insecticide resistance by alteration of gene dominance and migration. J Econ Entomol 72:105-109

Vergeer P, Sonderen E, Ouborg NJ (2004) Introduction strategies put to the test: Local adaptation versus heterosis. Conserv Biol 18:812-821

West-Eberhard MJ (2003) Developmental plasticity and evolution. Oxford Univ Press, New York

Workman MS, Leamy LJ, Routman EJ, Cheverud JM (2002) Analysis of QTL effects on the size and shape of mandibular molars in mice. Genetics 160:1573-1586

Wu R (1998) The detection of plasticity genes in heterogeneous environments. Evolution 52:967-977

Zar JH (1999) Biostatistical analysis. Prentice Hall, New Jersey 